PREPARED FOR THE U.S. DEPARTMENT OF ENERGY, UNDER CONTRACT DE-AC02-76CH03073

PPPL-3994

PPPL-3994

UC-70

\title{
A High-speed Optical Diagnostic that uses Interference Filters to Measure Doppler Shifts
}

by

S.F. Paul, C. Cates, M. Mauel, D. Maurer,

G. Navratil, and M. Shilov

August 2004

$\left.\stackrel{M}{M}\right|_{\substack{\text { PRInCETON PLASIMA } \\ \text { PHYSICS LABORATORY }}} ^{D}$

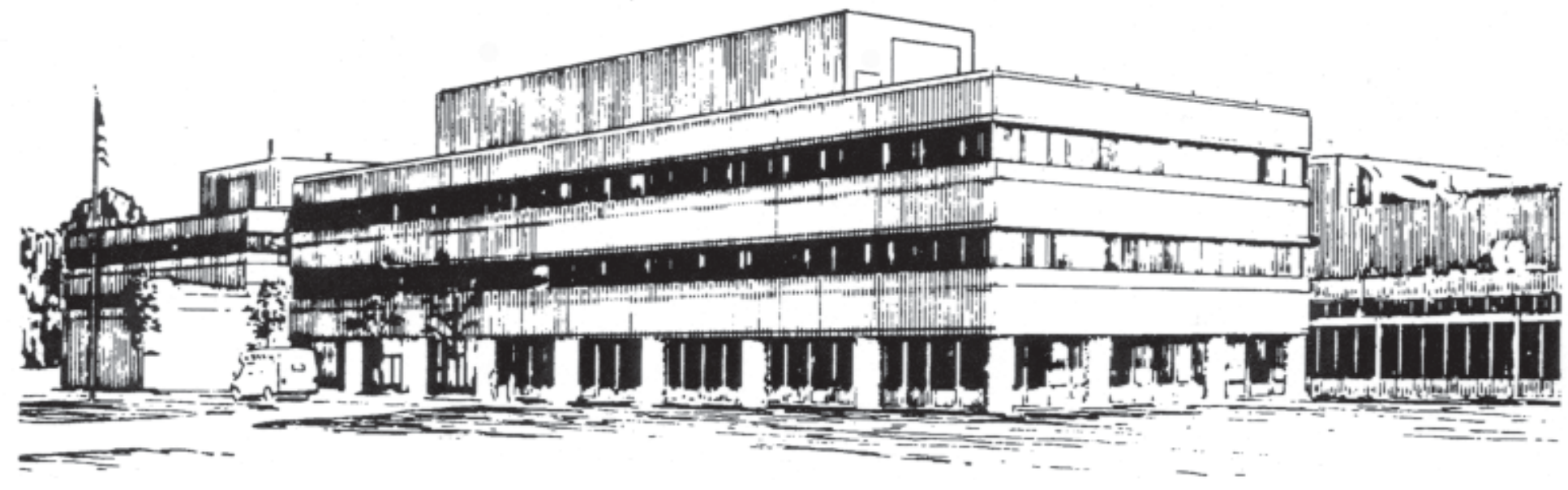

PRINCETON PLASMA PHYSICS LABORATORY PRINCETON UNIVERSITY, PRINCETON, NEW JERSEY 


\section{PPPL Reports Disclaimer}

This report was prepared as an account of work sponsored by an agency of the United States Government. Neither the United States Government nor any agency thereof, nor any of their employees, makes any warranty, express or implied, or assumes any legal liability or responsibility for the accuracy, completeness, or usefulness of any information, apparatus, product, or process disclosed, or represents that its use would not infringe privately owned rights. Reference herein to any specific commercial product, process, or service by trade name, trademark, manufacturer, or otherwise, does not necessarily constitute or imply its endorsement, recommendation, or favoring by the United States Government or any agency thereof. The views and opinions of authors expressed herein do not necessarily state or reflect those of the United States Government or any agency thereof.

\section{Availability}

This report is posted on the U.S. Department of Energy's Princeton Plasma Physics Laboratory Publications and Reports web site in Fiscal Year 2004. The home page for PPPL Reports and Publications is: http://www.pppl.gov/pub_report/

DOE and DOE Contractors can obtain copies of this report from:

U.S. Department of Energy

Office of Scientific and Technical Information

DOE Technical Information Services (DTIS)

P.O. Box 62

Oak Ridge, TN 37831

Telephone: (865) 576-8401

Fax: (865) 576-5728

Email: reports@adonis.osti.gov

This report is available to the general public from:

National Technical Information Service

U.S. Department of Commerce

5285 Port Royal Road

Springfield, VA 22161

Telephone: $1-800-553-6847$ or

(703) $605-6000$

Fax: (703) 321-8547

Internet: http://www.ntis.gov/ordering.htm 


\title{
A High-Speed Optical Diagnostic that Uses Interference Filters to Measure Doppler Shifts
}

\author{
S.F. Paul \\ Plasma Physics Laboratory \\ Princeton University \\ Princeton, New Jersey 08543-0451 \\ C. Cates, M. Mauel, D. Maurer, G. Navratil, M. Shilov \\ Dept. of Applied Physics and Applied Mathematics \\ Columbia University \\ New York, NY 10027
}

\begin{abstract}
A high-speed, non-invasive velocity diagnostic has been developed for measuring plasma rotation. The Doppler shift is determined by employing two detectors that view line emission from the identical volume of plasma. Each detector views through an interference filter having a passband that varies linearly with wavelength. One detector views the plasma through a filter whose passband has a negative slope and the second detector views through one with a positive slope. Because each channel views the same volume of plasma, the ratio of the amplitudes is not sensitive to variations in plasma emission. With suitable knowledge of the filter characteristics and the relative gain, the Doppler shift is readily obtained in realtime from the ratio of two channels without needing a low throughput spectrometer. The systematic errors - arising from temperature drifts, stability, and frequency response of the detectors and amplifiers, interference filter linearity, and ability to thoroughly homogenize the light from the fiber bundle - can be characterized well enough to obtain velocity data with \pm 1 $\mathrm{km} / \mathrm{sec}$ with a time resolution of $0.3 \mathrm{msec}$.
\end{abstract}




\section{Introduction}

Measurements of plasma rotation have been important in fusion research for decades with theories of parallel impurity velocity based on neoclassical effects first developed in the 1970's. ${ }^{1}$ In neutral beam experiments in particular, the effects of momentum transport are important as plasmas are accelerated to supersonic velocities. Using a variety of techniques, including magnetic probes, Mach probes ${ }^{2}$, streak photography, and spectroscopic measurements ${ }^{3}$ (including charge exchange measurements on neutral beams ${ }^{4}$ ), physicists have used rotation measurements to examine issues involving transport, instabilities, $\beta$-limits, and the effects of radial electric fields. High-resolution, low throughput spectrometers ${ }^{5}$ have been built and successfully used for diagnosing fusion plasmas even with low rotation. The disadvantages are cost and data collection speed. Other spectroscopic techniques developed more recently, such as the MOSS camera system, employ time-delayed Fourier Transform Spectroscopy and other optical coherence techniques in the time domain. ${ }^{6}$ This enhances the optical throughput by eliminating the need for an entrance slit. ${ }^{7}$

In this paper, a non-invasive velocity measurement is presented that also eliminates the need for a grating spectrometer, allowing for reduced expense, highthroughput and fast time response. This diagnostic has been developed for use on Columbia's HBT-EP, a tokamak designed to examine the feasibility of high-beta operation stabilized with a combination of close-fitting conducting walls, plasma rotation, and active feedback. ${ }^{8}$ In particular, the MHD stabilization program includes using a biased edge probe as well as fast feedback control of the plasma rotation relative to the conducting wall. The plasma parameters are: $92-97 \mathrm{~cm}$ major radius, $15-$ $19 \mathrm{~cm}$ minor radius, $<15 \mathrm{kA}$ plasma current, $3 \mathrm{kG}$ toroidal field, $<80 \mathrm{eV}$ central electron temperature, and $<10^{13} \mathrm{~cm}^{-3}$ electron density. 
The goal of the HBT-EP program is to observe toroidal rotation at the $\mathrm{q}=2$ surface at $\mathrm{r} / \mathrm{a}=0.75$ where magnetic islands form. In this region about $4 \mathrm{~cm}$ from the plasma's edge, the estimated temperature is 10 to $20 \mathrm{eV}$ so the intense He II ( $4 \mathrm{f} \rightarrow 3 \mathrm{~d}$ ) line complex at $468.6 \mathrm{~nm}$ is used. At $54.4 \mathrm{eV}$, the ionization potential of $\mathrm{He}^{+}$is large enough to prevent burnthrough in a $10-20 \mathrm{eV}$ plasma if the ion confinement times are $<1 \mathrm{msec}$, as is likely in HBT-EP where the pulse lengths are typically $6-8 \mathrm{msec}$. Adequate emission from the He II line has been measured on HBT-EP in deuterium plasmas that are seeded with $10 \%$ helium.

The novel aspect of this technique is that the Doppler shift is calculated from the ratio of the light intensity from two detectors rather than by resolving the emission line with a grating spectrometer. The ratio of the signal intensities, each split from the optical path, is not sensitive to changes in plasma emission because the two detectors are made to observe the identical volume of plasma. But passing the light in one channel through an interference filter having a passband with a negative slope and in the other channel through a positive-slope bandpass filter does modify the signal ratio if the emission line is shifted, as shown in Figure 1. For linear bandpass filters, the ratio is not sensitive to changes in the ion temperature. Modeling the filter transmission functions in the linear passband region as $T_{ \pm}(\lambda)=\left(a_{ \pm} \lambda+b_{ \pm}\right)$, where \pm denotes the filter with either a positive or negative slope, the equation that relates the Doppler shifted wavelength to the signal ratio $\rho$ is simple and can easily be performed in real time ${ }^{9}$

$$
\lambda=\frac{\rho\left(b_{-} / a_{-}\right)-R_{G}\left(b_{+} / a_{+}\right)\left(a_{+} / a_{-}\right)}{R_{G}\left(a_{+} / a_{-}\right)-\rho}
$$

where $R_{G}=G_{+} / G_{-}$is the relative gain (including the splitter ratio, insertion losses, detector response, digitizer response as well as amplfier gain) between the two 
channels with both filters removed. Eq. 1 shows that aside from fixed parameters that depend on the total relative gain, e.g., detector / amplifier sensitivity, fiber losses, optical filter passbands, etc., the Doppler shift is a function of the ratio of the output signals only. The questions addressed in this paper are concerned with whether the:

1. light path is split with adequate homogeneity to insure that the detectors view the identical volume of plasma,

2. interference filters passbands are satisfactorily linear and reliably calibrated,

3. amplitude and phase difference of the detectors and amplifiers can be calibrated with sufficient precision to obtain velocity data with acceptable resolution.

\section{Uniformity of the Splitting of the Light Path}

Ensuring the viewing of identical volumes is complicated by the low density and modest Ohmic heating capability in HBT-EP. The light is transmitted from the tokamak to the detectors via a bundle of seven 1-mm diameter silica fibers as shown in Figure 1. The magnification due to the imaging lens at the tokamak is 16 so the collection area in the plasma of the fiber bundle is $11 \mathrm{~cm}$ high by $1.6 \mathrm{~cm}$ wide. Because spatial fluctuations in the plasma emission over the $18 \mathrm{~cm}^{2}$ viewing area are likely cause individual fibers to observe regions of different emission, the light must be thoroughly homogenized. This is accomplished by using two approaches:

1. Splitting the light with ' $Y$ ' fiber bundle comprised of about $30060 \mu \mathrm{m}$ diameter close packed randomized fibers.

2. Inserting a mode mixer, a 100-mm long, 3-mm diameter silica rod with polished ends, butt-coupled to the bundle with index matching gel. The intrinsic $\mathrm{f} / \mathrm{no}$. of one tenth of the rod length is $100 / 3 / 10=3.3$, so except for $1 /(4 \times f / \text { no. })^{2}$ or $0.5 \%$ of the flux, the light is internally reflected in the rod at least ten times. 
The resulting uniformity of the combined light is illustrated in Figure 3, which superimposes three images of the bundle. The leftmost depicts one branch of the bundle backlit with a red LED and the rightmost the other branch with a blue LED. The center image is with both branches illuminated. The combined purple image has a uniform color.

\section{Linearity of the Interference Filters}

The modeled bandpass shapes for the positive and negative slope filters, as ordered from Barr Associates, Westford, MA are shown in Figure 2. The asymmetry designed into the passbands maximize the width of the linear region of the transmission function as well as the sharpness of the slope. Filters at $468.6 \mathrm{~nm}$ with steep passband slopes (100 - 200\% per $\mathrm{nm}$ ) and less than a $0.1 \%$ deviation from linearity over a $0.2 \mathrm{~nm}$ width were procured from Barr. The sensitivity of the signal ratio to shifts in wavelength was measured by using a slit spectrometer with a $0.05 \mathrm{~nm}$ instrumental width to illuminate the fiber splitter. For the filters as manufactured, the ratio as a function of the incident wavelength is shown in Figure 4. The variation of the signal ratio to wavelength is quite sensitive: the signal ratio changes by nearly a factor of 2 for about only $0.1 \mathrm{~nm}$ of shift, confirming that a signal resolution of $1 \%$ can detect a wavelength shift of only $0.001 \mathrm{~nm} .^{9}$

In principal the shifted wavelength may be found by simply interpolating from Figure 4 and generating a look-up table, a better adjustment of the filters is achieved by identifying the linear region and model it as in Ref. 9. Because $T_{+} / T_{-}$is not a linear function of wavelength, it is difficult to judge from Figure 4 whether the filters are properly tilt-tuned, i.e., whether the linear regions from both filters coincide as idealized in Figure 2. Furthermore, because the instrumental width of the calibrating spectrometer is $.05 \mathrm{~nm}, 50$ times coarser the desired wavelength resolution, the points 
in Figure 4 are actually a fairly rough indicator. The knowledge that the slopes are be linear becomes a very important constraint. So in practice, after tilting the filters so the linear regions appear to coincide, $b_{ \pm} / a_{ \pm}$in Eq. 1 is calculated from a linear fit to each filter's passband. Then the points in Figure 4 that are judged to be in the overlapping linear region are used to determine $a_{+} / a_{-}$from a linear least-squares fit. Note that any parameters that include $b_{ \pm}$depend on the tilt angle of the filter and the ambient temperature. The filter constants cannot be "precalibrated" on an optical bench, but must be determined in situ with no adjustments once the calibration is completed. An industrial grade temperature controller is sufficient to keep the temperature variation of the filter housing to within $\pm 0.1^{\circ} \mathrm{C}$, enough to keep the filter "constants" from drifting.

The result is shown in Figure 5, a plot of the calculated shifted wavelength versus the actual wavelength of incident light. The wavelength is calculated by simply substituting the measured signal ratio from Figure 4 into Eq. 1 . The result shows that between 486.5 and $486.7 \mathrm{~nm}$, the calculated value of shifted wavelength is correlated almost perfectly $(\mathrm{R}=0.9997)$ with the measured value. Recent filter modeling by Barr shows that the width of the linear region should be able to be expanded to $0.4 \mathrm{~nm}$.

\section{Calibration of the Frequency Response of the Detectors/Amplifiers}

Amplitude and phase calibration is vital to prevent the measured signal ratio at a given harmonic from being distorted by variations in relative gain or phase shift in the detectors/amplifiers. For calibrating, the input signals are applied to the detectors optically so that no capacitive loading from connecting leads distort the measurement. An LED, driven by a frequency generator is used to illuminate the trunk of the fiber optic "Y" with a swept sinusoid as shown in Figure 6. The signals are recorded with the same anti-aliasing filters and LeCroy 6810 digitizer that are used for taking plasma data. 
The amplifiers used are medium bandwidth (400 kHz frequency response) circuits, very low-noise current-to-voltage converters originally developed for use in optical diagnostics on TFTR. ${ }^{10}$ The circuit employs a biased high quantum efficiency FFD-040 PIN photodiode that, unlike a PMT whose gain drifts in time or an APD whose response varies strongly with temperature, has a very stable responsivity. Lack of internal photoelectron multiplication of course is paid for by low light sensitivity and amplifier noise limits detectability. This circuit is designed to significantly reduce the Johnson noise and input voltage noise compared to conventional transimpedance amplifiers. The amplifier has four stages:

1. A very low noise external FET to match the capacitance of the detector

2. A low frequency response preamp $\left(f_{3 \mathrm{db}}=300 \mathrm{~Hz}, \mathrm{R}_{\mathrm{f}}=300 \mathrm{M} \Omega\right)$ essentially an integrator)

3. A wideband frequency compensation circuit (essentially a differentiator to restore the frequency response)

4. A final voltage gain and anti-aliasing amplifier. Though the stages were designed to complement each other so the overall frequency response is flat, there are small deviations around the breakpoints, particularly the one at the $300 \mathrm{~Hz}$ cutoff frequency of the first stage. The signal generator used for calibration could sweep for no longer than $20 \mathrm{msec}$, so the frequency resolution is $\geq 50$ $\mathrm{Hz}$, adequate to reasonably resolve the $300 \mathrm{~Hz}$ cutoff. Unfortunately, the generator can sweep only a decade and a half in frequency at each frequency setting (a factor of 40) so the calibration had to be broken into successive frequency bands, rendering the process somewhat tedious. The first frequency band calibrated is illustrated in Figure 6 where the generator swept from $50 \mathrm{~Hz}$ to $2 \mathrm{kHz}$. The calibration sequence is: 
- Sample at $10 \mathrm{kHz}$ to keep Nyquist frequency well above the maximum $2 \mathrm{kHz}$ to be measured

- Use 256 points per segment, so the duration is 25.6 msecs, enough to record each sweep from the generator, as shown at the top of Figure 6.

- To utilize all the 524K samples in the digitizer memory, take 2048 segments (for a total duration of 52 seconds).

Because the sweep duration is analog controlled, it tends not to be exactly $25.6 \mathrm{msec}$, so synchronization with the data window is lost after dozens of pulses. This is easily tracked and compensated in the software, albeit needing some manual interaction. FFT's are performed on each segment and the auto and cross spectra are calculated. With 2048 segments to average, the relative error is $2.2 \%$. To further reduce calibration error to less than $1 \%$, five of the 52-second long "shots" were averaged.

The second trace and third traces in Figure 6 show the relative amplitude response and the phase shift up to $2.5 \mathrm{kHz}$. The amplitude response varies by $3-4 \%$. The phase shift varies by almost $2^{\circ}$ up to the breakpoint at $300 \mathrm{~Hz}$, and then is fairly constant, clearly showing the need for a calibration with good frequency resolution.

This calibration procedure must be repeated twice more for frequencies corresponding to the $500 \mathrm{~Hz}$ to $20 \mathrm{kHz}$ and $5 \mathrm{kHz}$ to $200 \mathrm{kHz}$ bands. The calibration sequences were analogously determined, e.g., for $500 \mathrm{~Hz}$ to $20 \mathrm{kHz}$, the sample rate was increased to $100 \mathrm{kHz}$ to maintain the Nyquist criterion. To sample the $20 \mathrm{msec}$ swept pulse, 256 segments of 2048 points were taken. Due to the lower number of segments per shot, 16 shots were averaged to reduce to relative error to $1.6 \%$. By 20 $\mathrm{kHz}$, the relative amplitude response variation increased to $10 \%$-- ten times the expected variation from the Doppler shift -- and the phase shift increased to almost $3.5^{\circ}$.

\section{Results}


All the systematic errors due to variations in plasma intensity, filter linearity, and frequency response conspire to exhibit spurious Doppler shifts. Fortunately, the results of all these calibrations can be tested easily. Simply viewing the plasma perpendicular to the anticipated particle flow ideally results in a constant signal ratio over time. This is shown for a HBT-EP discharge in Figure 7 where the top trace shows the signal from each channel. They are nominally identical, showing the burnout of the initial helium content in the fill gas, followed by a more steady level representing the flow of neutral helium from the edge. The fluctuations of $20 \%$ or so in the intensity are due to reconnection events such as edge modes and sawteeth. The time history of the signal ratio is also shown in Figure 7, after adjusting for relative detector calibration and applying a $3 \mathrm{kHz}$ low-pass digital filtering. The variation in the signal is less than $\pm 1 \%$, with the large amplitude oscillations before and after the discharge resulting from a divide-by-zero error in the ratio when no light is present. The calculation of the wavelength shift from Eq. (1) shows that throughout the time history, the error in the wavelength shift is less than $0.001 \mathrm{~nm}$ and the corresponding ion velocity excursion i.e., $v_{\text {ion }}=(\lambda-\langle\lambda\rangle /\langle\lambda\rangle) c$-- is less than $\pm 1 \mathrm{~km} / \mathrm{sec}$. With more light available, e.g., from a strongly heated plasma dissipating more power in a high density edge, this diagnostic should be able to discern a corresponding lower minimum rotation velocity.

Returning the detector to its tangential view shows the toroidal rotation in HBTEP. In $1 \mathrm{~km} / \mathrm{sec}$.

Figure 8, the plasma rotation accelerates to $5 \mathrm{~km} / \mathrm{sec}$ while the plasma is heated, as indicated by the increasing soft X-ray signal. Even without position feedback control, the radial equilibrium is maintained from 2 to $7 \mathrm{msec}$; the major radius changes by only about $0.5 \mathrm{~cm}$. At $4 \mathrm{msec}$, an $\mathrm{n}=2$ mode begins to grow and by $5 \mathrm{msec}$, the plasma stops 
accelerating. At $6 \mathrm{msec}$, a burst in the $\mathrm{n}=2$ signal shows a sudden braking of the plasma that is coincident with a magnetic reconnection event and an abrupt drop in temperature. But after the event, the SXR signal recovers and the plasma quickly reaccelerates to $5.5 \mathrm{~km} / \mathrm{sec}$. At $6.5 \mathrm{msec}$, the plasma brakes strongly, becoming locked at 7 msec. At this instant, the MHD signal again increases dramatically, and the plasma temperature crashes. The plasma immediately disrupts, indicated by the loss of radial equilibrium.

In many HBT-EP discharges, strong damping of the rotation is coincident with spikes in magnetic mode activity and sudden jogs in major radius due to changes in magnetic equilibrium. In plasmas with minor disruptions, the rotation is observed to drop suddenly during these spikes and accelerate rapidly afterwards. If the rotation is completely braked, the plasma always terminates immediately in a major disruption.

\section{Acknowledgements}

Support from S. Zweben and the assistance of Columbia University's HBT-EP technical crew is greatly appreciated. This research has been supported by U.S. DoE contracts No. DE-AC02-76-CHO-3073 and No. DE-FG02-86ER-53222. 


\section{References}

${ }^{1}$ Hazeltine, R.D., Phys. Fluids, 17, (1974) 961.

2 Stangeby, P.C., Phys. Fluids, 27, 11 (1984) 2699.

${ }^{3}$ Bell, M.G., Nuc. Fus., 19, 1 (1979) 33.

${ }^{4}$ Fonck, R.J., Darrow, D.S., Jaehnig, K.P., Physical Review A, 29, 6 (1984) 3288.

${ }^{5}$ Rowan, W., and Meigs, A.G. et al., Rev. Sci. Instrum., 61, 2952 (1990).

${ }^{6}$ Howard, J., Michael, C., Glass, F. and Cheetham, A.D., Rev. Sci. Inst., 72, 1 (2001) 888.

${ }^{7}$ Howard, J., Rev. Sci. Instrum., 70, 1 (1999) 368.

${ }^{8}$ Shilov, M., Cates, C., et al., Phys. Plasma, 11, 5 (2004) 2573-2579.

${ }^{9}$ Paul, S.F., Rev. Sci. Instrum., 74, 3 (2003) 2098-2102.

10 Fonck, R. J., Ashley, R. , Durst, R. , et al. , Rev. Sci. Instrum. 63, 4924 (1992). 


\section{List of Figure Captions}

Figure 1. The experimental apparatus on the HBT-EP tokamak is designed to have two detectors view the identical volume of plasma so that the effect of changing plasma intensity is removed. The fiber bundle is comprised of 7 1-mm diameter PCS fibers. The mode mixer is a 4 inch long $3 \mathrm{~mm}$ diameter rod made of fused silica. The optical splitter contains about 300 close packed fibers in random locations.

Figure 2 . Illustration of the measurement method: two interference filters examine the impurity line that is positioned in the overlaping linear region of the filters' passbands. As the line is Doppler shifted (in this illustration towards the red), the ratio of the light intensity is modified.

Figure 3. Three superposed images of the back-illuminated 7-fiber optic bundle which qualitatively illustrates the degree of uniformity achieved with the mode-mixer/beamsplitter combination. The leftmost image is with one leg of the " $Y$ " backlit with a red LED. The rightmost image depicts the other leg of the " $Y$ " backlit with a blue LED. The center image is with both legs backilluminated. To limit the loss of radial resolution, the bundle is curved to match the curvature of the poloidal flux contours.

Figure 4. Illustration of variation in signal ratio with wavelength for the manufactured filters with light incident on the input optics.

Figure 5. Illustration of the linearity achieved for the manufactured filters. The calculated wavelength using the filter parameters is compared with the actual incident wavelength. The linear region of filter is at least a $0.2 \mathrm{~nm}$ wide. 
Figure 6. (a) Swept frequency light pulse, which is one of 2048 segments of 256 points each. (b) Relative amplitude response of the two detector circuits from 0 to $2 \mathrm{kHz}$. (c) Phase shift between the output signals, showing the breakpoint at the $300 \mathrm{~Hz}$ cutoff frequency of transimpedance amplifier in the first stage.

Figure 7. Traces of signals measured on HBT-EP viewing perpendicularly to the plasma flow. Upper trace is the raw signal into each of the detectors. The middle trace is the signal ratio, after frequency response calibration and $3 \mathrm{kHz}$ low pass filtering. The resulting spurious velocity is shown in the bottom trace. The peak deviation is less than $\pm 1 \mathrm{~km} / \mathrm{sec}$.

Figure 8. Results in HBT-EP plasmas with the normal tangential view. The upper trace shows the time history of the measured toroidal rotation. The other traces are the soft X-ray signal, the position of major radius, and the $\mathrm{n}=2$ magnetic pick-up coil signal. The times of the minor and major disruptions (.006 and .007 seconds) are shown by the two vertical bars. 


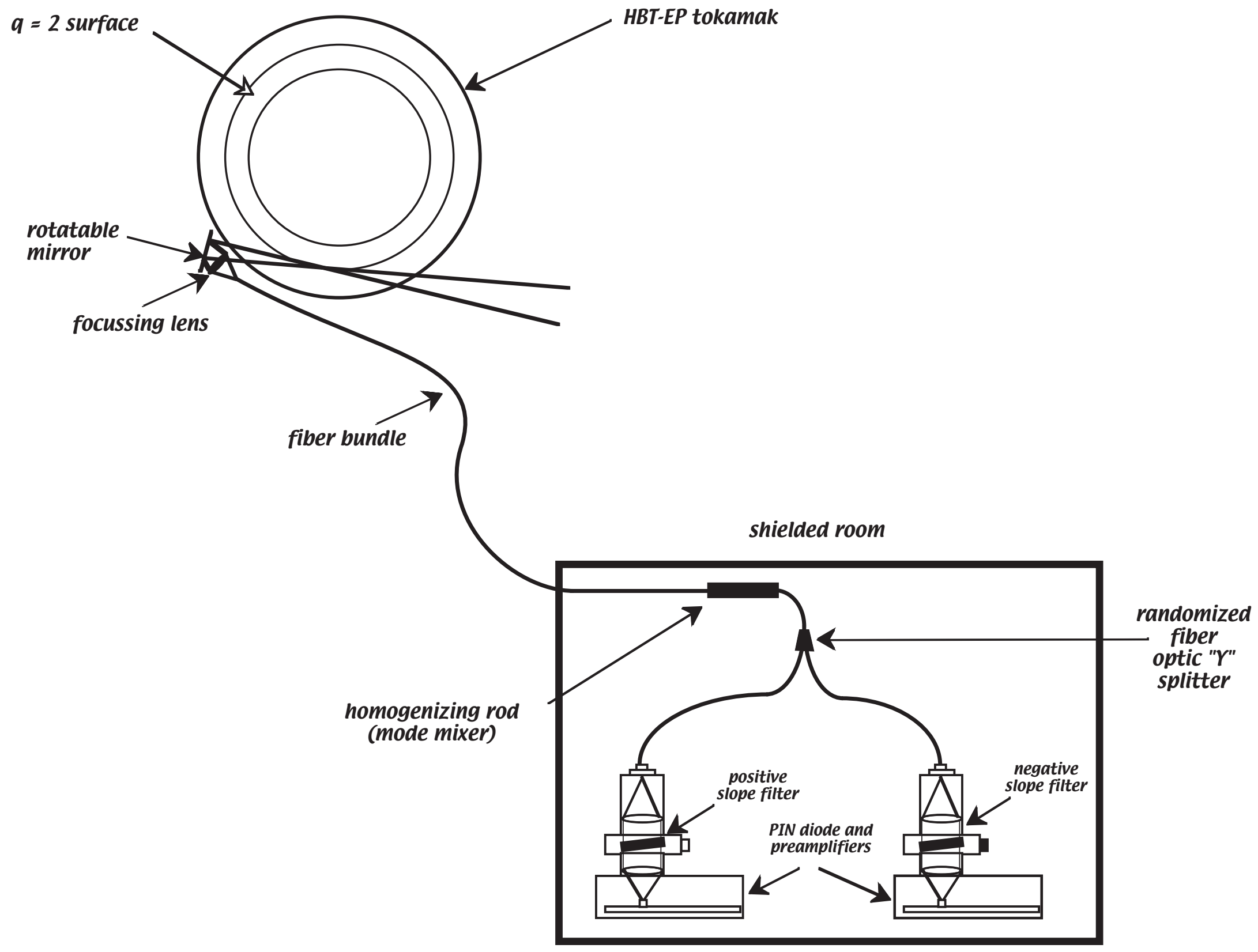

Figure 1, S.F. Paul, Poster \#F01 


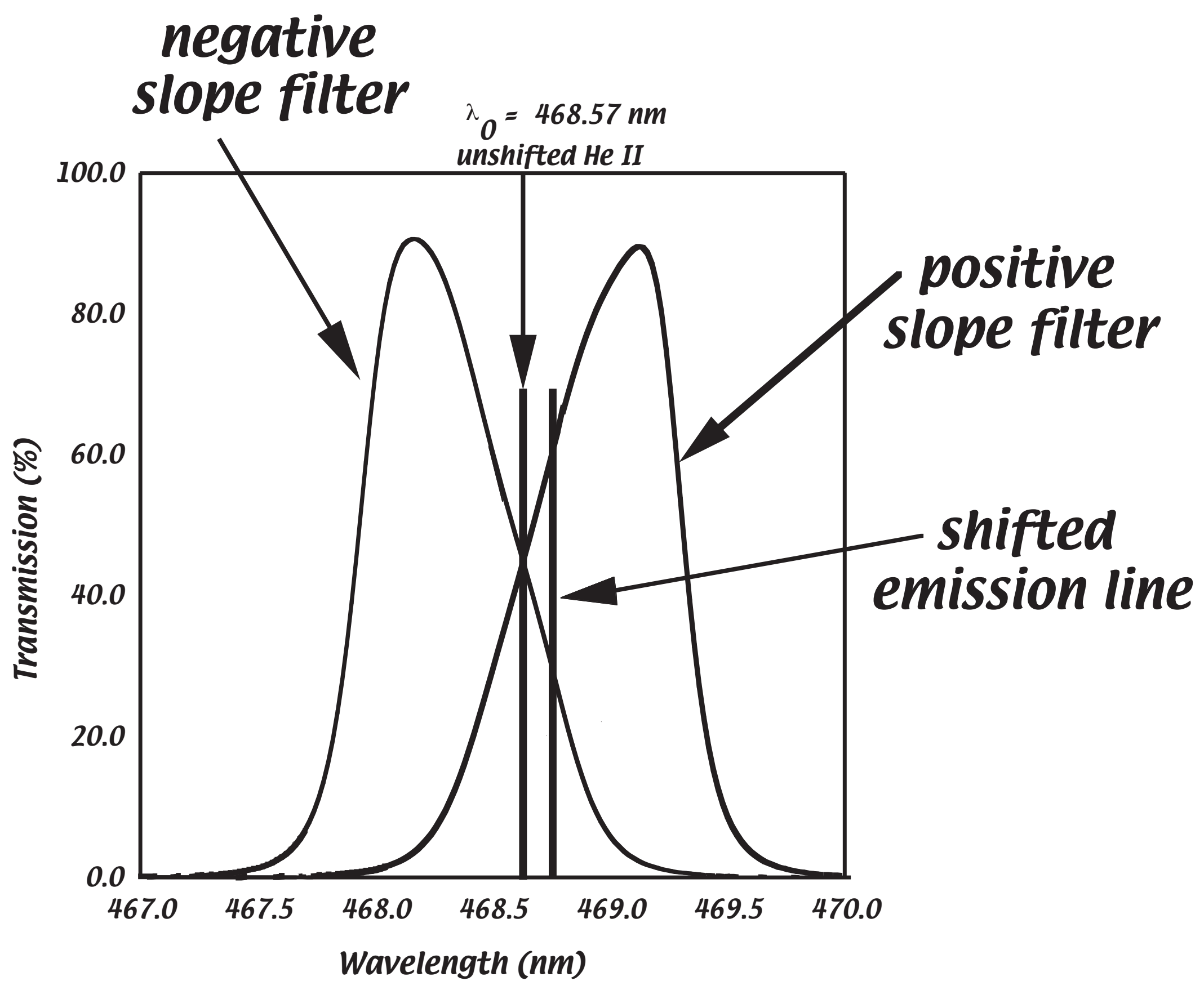

Figure 2, S.F. Paul, \#F01 


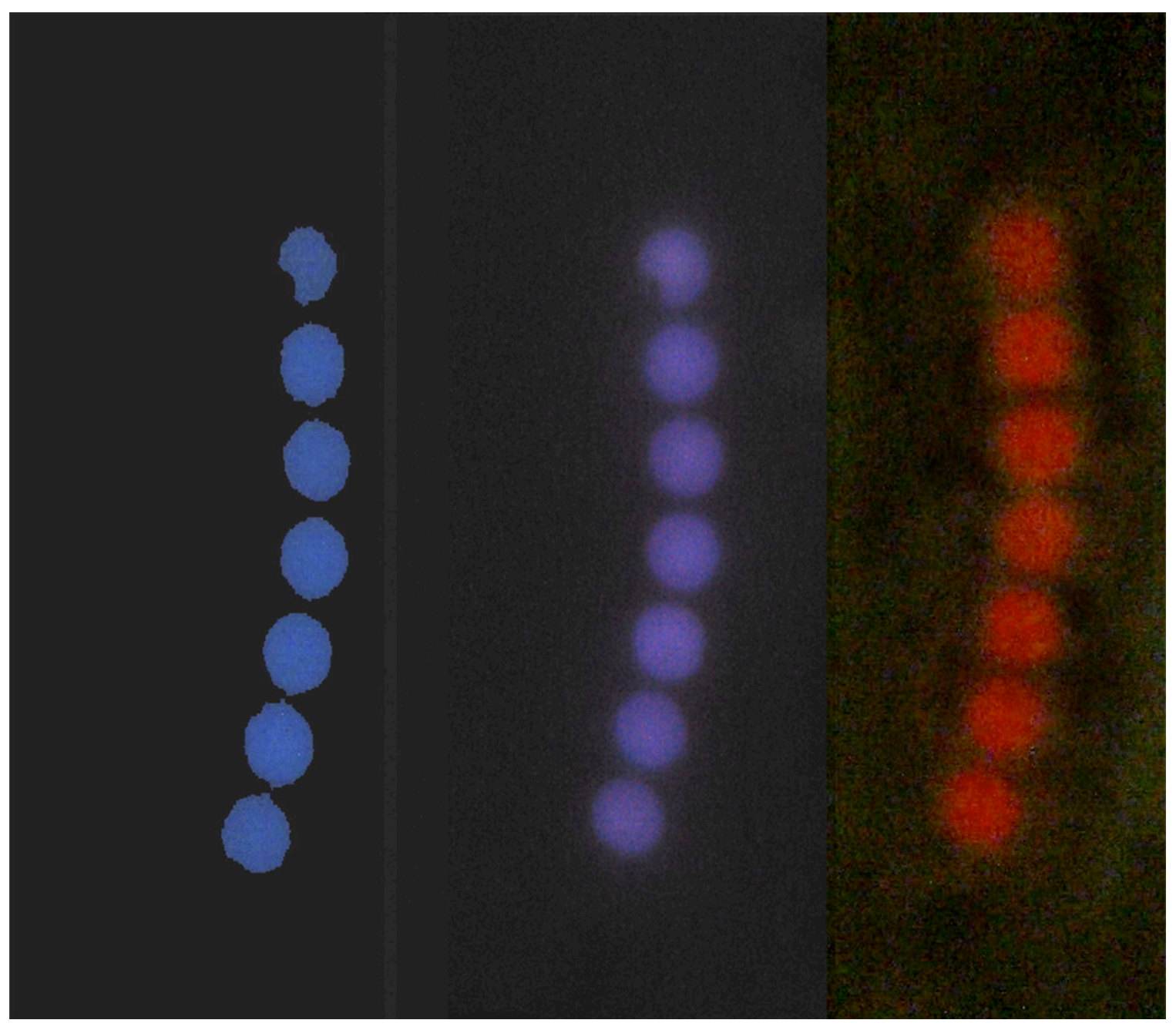

Figure 3, SF. Paul, \#F01 


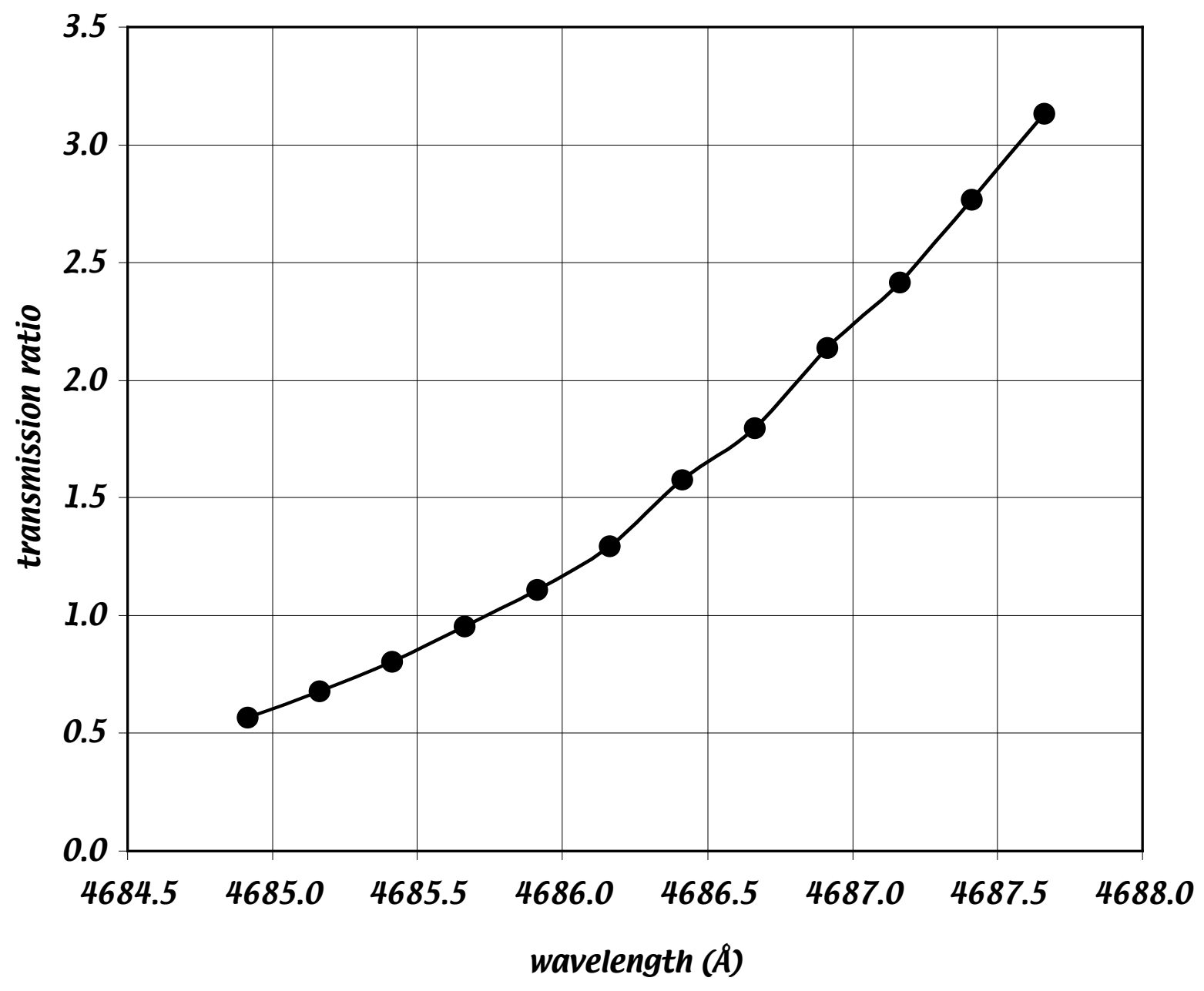

Figure 4, SF. Paul, \#F01 


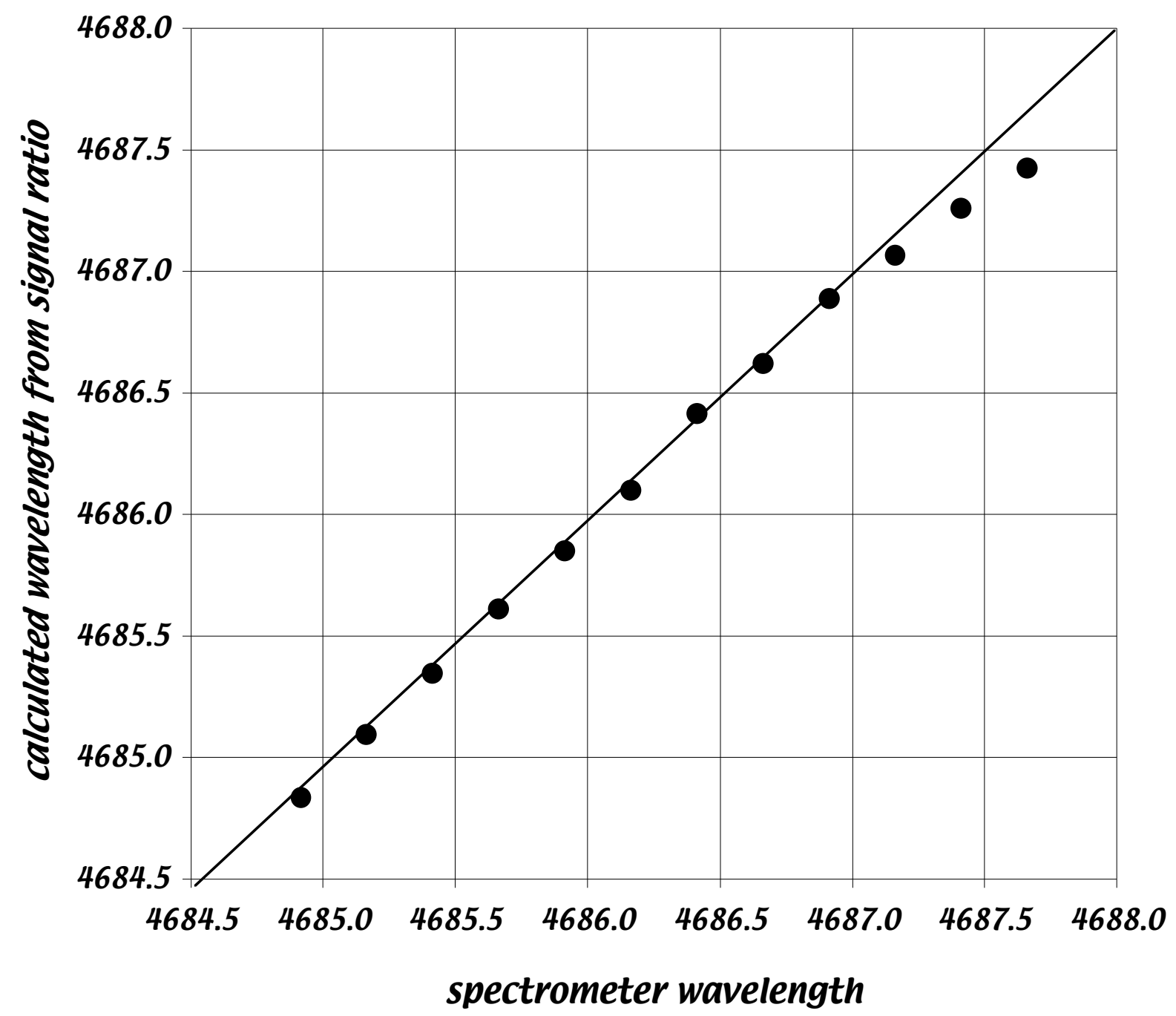

Figure 5, SF. Paul, \#F01 

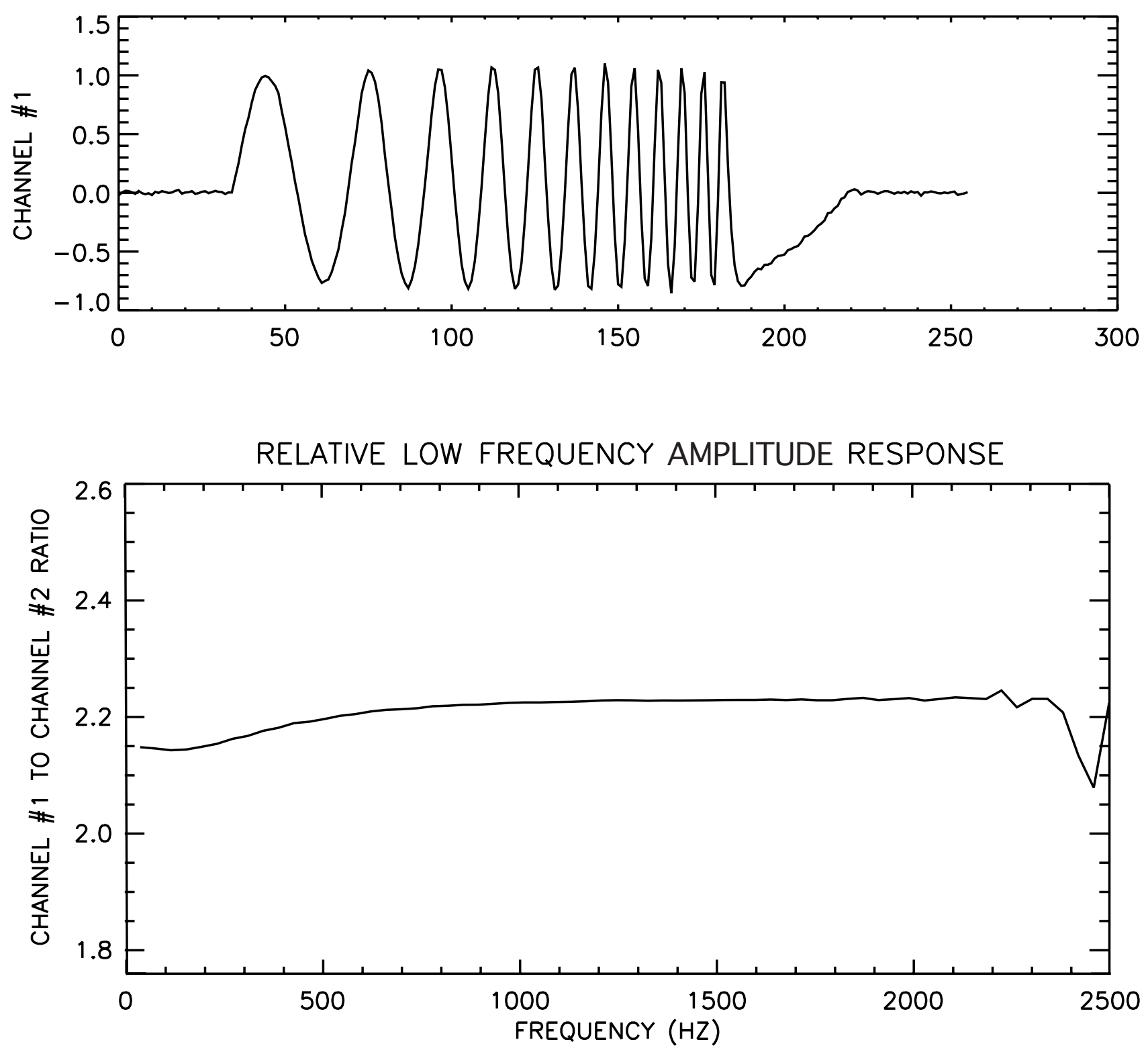

LOW FREQUENCY PHASE SHIFT

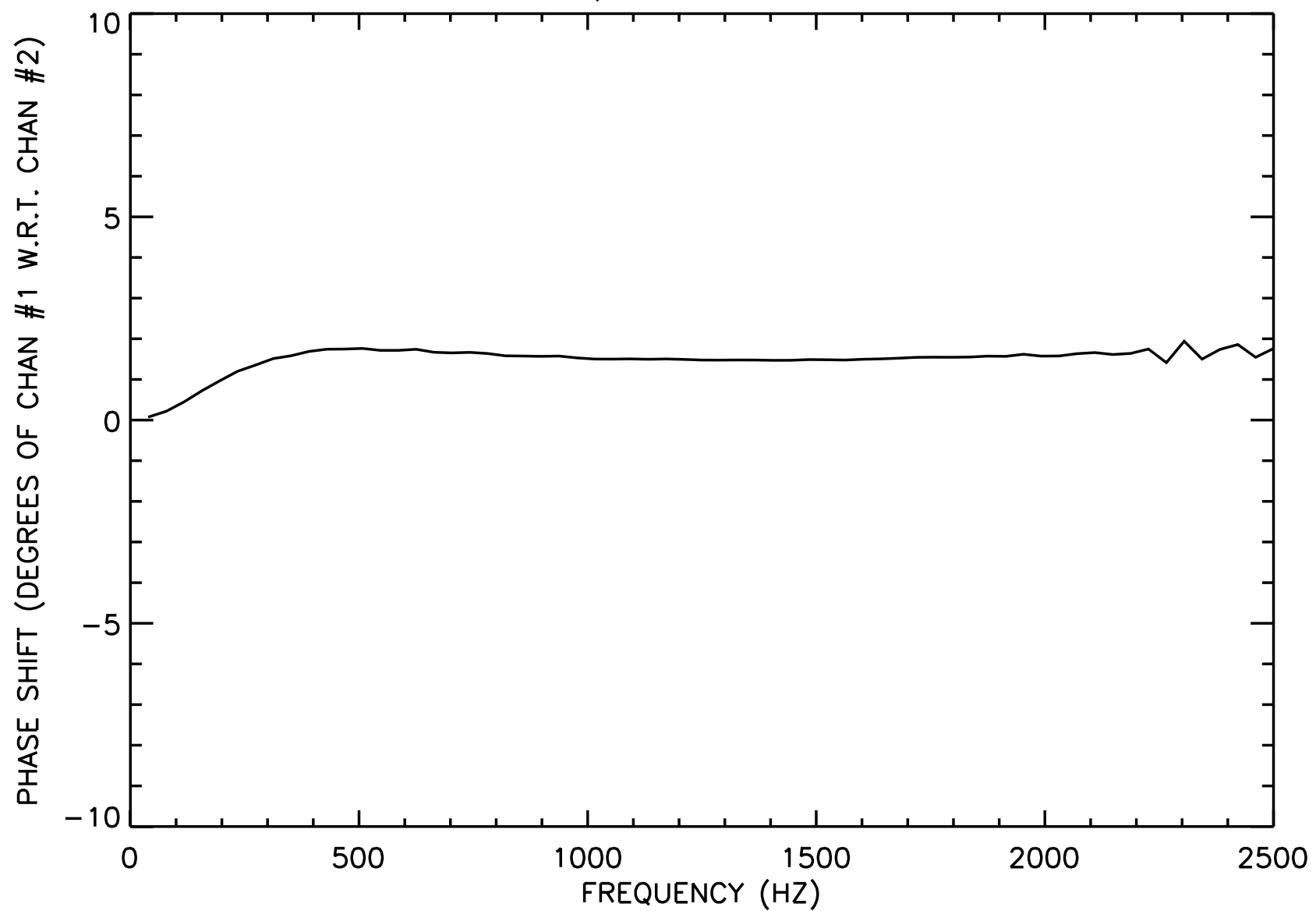

Figure 6, S.F. Paul \#F01 

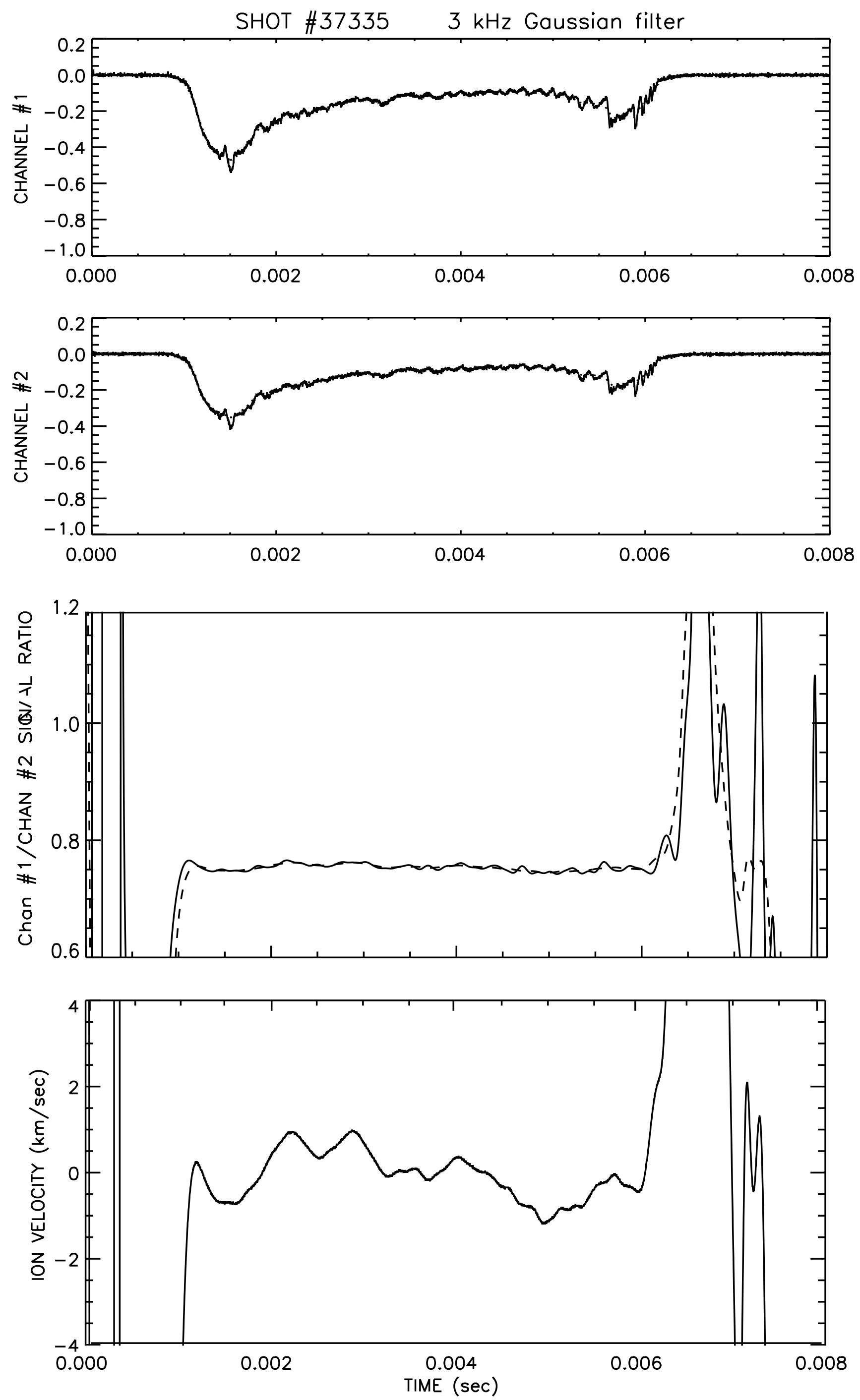

Figure 7, S.F. Paul, \#FO1 

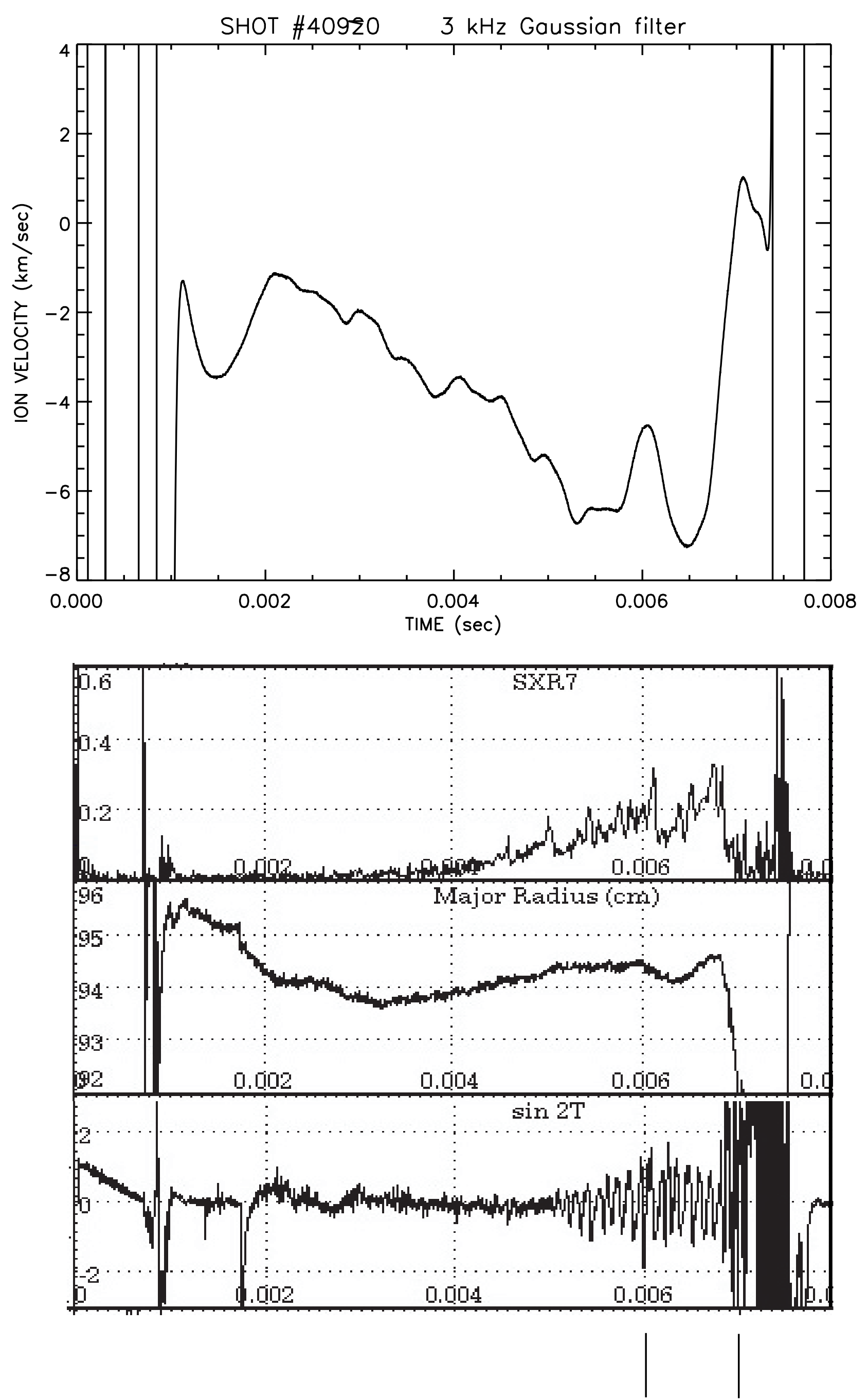

Figure 8, S.F. Paul, \#F01 


\section{External Distribution}

Plasma Research Laboratory, Australian National University, Australia

Professor I.R. Jones, Flinders University, Australia

Professor João Canalle, Instituto de Fisica DEQ/IF - UERJ, Brazil

Mr. Gerson O. Ludwig, Instituto Nacional de Pesquisas, Brazil

Dr. P.H. Sakanaka, Instituto Fisica, Brazil

The Librarian, Culham Laboratory, England

Mrs. S.A. Hutchinson, JET Library, England

Professor M.N. Bussac, Ecole Polytechnique, France

Librarian, Max-Planck-Institut für Plasmaphysik, Germany

Jolan Moldvai, Reports Library, Hungarian Academy of Sciences, Central Research Institute for Physics, Hungary

Dr. P. Kaw, Institute for Plasma Research, India

Ms. P.J. Pathak, Librarian, Institute for Plasma Research, India

Ms. Clelia De Palo, Associazione EURATOM-ENEA, Italy

Dr. G. Grosso, Instituto di Fisica del Plasma, Italy

Librarian, Naka Fusion Research Establishment, JAERI, Japan

Library, Laboratory for Complex Energy Processes, Institute for Advanced Study, Kyoto University, Japan

Research Information Center, National Institute for Fusion Science, Japan

Dr. O. Mitarai, Kyushu Tokai University, Japan

Dr. Jiangang Li, Institute of Plasma Physics, Chinese Academy of Sciences, People's Republic of China

Professor Yuping Huo, School of Physical Science and Technology, People's Republic of China

Library, Academia Sinica, Institute of Plasma Physics, People's Republic of China

Librarian, Institute of Physics, Chinese Academy of Sciences, People's Republic of China

Dr. S. Mirnov, TRINITI, Troitsk, Russian Federation, Russia

Dr. V.S. Strelkov, Kurchatov Institute, Russian Federation, Russia

Professor Peter Lukac, Katedra Fyziky Plazmy MFF UK, Mlynska dolina F-2, Komenskeho Univerzita, SK-842 15 Bratislava, Slovakia

Dr. G.S. Lee, Korea Basic Science Institute, South Korea

Institute for Plasma Research, University of Maryland, USA

Librarian, Fusion Energy Division, Oak Ridge National Laboratory, USA

Librarian, Institute of Fusion Studies, University of Texas, USA

Librarian, Magnetic Fusion Program, Lawrence Livermore National Laboratory, USA

Library, General Atomics, USA

Plasma Physics Group, Fusion Energy Research Program, University of California at San Diego, USA

Plasma Physics Library, Columbia University, USA

Alkesh Punjabi, Center for Fusion Research and Training, Hampton University, USA

Dr. W.M. Stacey, Fusion Research Center, Georgia Institute of Technology, USA

Dr. John Willis, U.S. Department of Energy, Office of Fusion Energy Sciences, USA

Mr. Paul H. Wright, Indianapolis, Indiana, USA 
The Princeton Plasma Physics Laboratory is operated by Princeton University under contract with the U.S. Department of Energy.

\author{
Information Services \\ Princeton Plasma Physics Laboratory \\ P.O. Box 451 \\ Princeton, NJ 08543
}

Phone: 609-243-2750

Fax: 609-243-2751

e-mail: pppl_info@pppl.gov

Internet Address: http://www.pppl.gov 